\title{
UM SONHO DE GRANDEZA NO BRASIL DA DITADURA: A IDEOLOGIA GEOPOLÍTICA DE DESENVOLVIMENTO DO GENERAL CARLOS DE MEIRA MATTOS (1964-1974)
}

\author{
Adriano Moura de Oliveira*
}

\begin{abstract}
Resumo: Se as Forças Armadas não foram as únicas a sonharem com um Brasil Potência Mundial, sem dúvida, tais ideias solidificaram-se nos quartéis chegando a transformarem-se num projeto da ditadura militar. Foi no pensamento geopolítico que essas ideias evoluíram com maior consistência, no qual esse plano Brasil Potência passou a fazer parte essencial daquilo que se discutia nos manuais e palestras. Esse artigo pretende percorrer os principais aspectos que permeiam o discurso geopolítico e seu modelo de desenvolvimento a partir de 1964. Objetivamos verificar como os fatores autoritários estiveram entrelaçados ao suposto ideal de grandeza nacional.
\end{abstract}

Palavras-chave: Forças Armadas, Ideologia, Geopolítica, Brasil Potência.

\begin{abstract}
A dream of greatness in Brazil Dictatorship: The General's Carlos de Meira Mattos (1964-1974) geopolitical ideology of development.

Abstract: If the Armed Forces were not the only ones to dream of Brazil World Power, without a doubt, such ideas had been consolidated in the headquarters becoming in a project of the military's dictatorship. It was in the geopolitical ideology that these ideas had mostly developed and in which this plan "Brazil World Power" started to be a essential part of what it argued in manuals and lectures. This article intends to cover the main aspects of the geopolitical speech and its models of development from 1964. We considered how the authoritarian factors had been interlaced to the ideal of national greatness.
\end{abstract}

Keywords: Armed Forces, Ideology, Geopolitics, Brazil World Power.

\footnotetext{
* Doutorando do Departamento de História da Universidade de São Paulo. Mestre em História pela PUC-SP.

Recebido em: 03/10/2013 - Aceito em: 16/07/2014.
} 
Un sueño de grandeza en Brasil de la dictadura: La ideología geopolítica del desarrollo del General Carlos de Meira Mattos (1.964 a 1.974).

Resumen: Si las fuerzas armadas no fueron las únicas que soñaron con un Brasil potencia mundial, sin duda, tales ideas se solidificaron en los cuarteles para transformar la dictadura militar en un proyecto. Fue en el pensamiento geopolítico que estas ideas se desarrollaron con mayor consistencia, en el que el plan del Brasil Potencia pasó a ser una parte esencial de lo que se discutió en los manuales y conferencias. Este artículo tiene la intención de recorrer los principales aspectos que permean el discurso geopolítico y su modelo de desarrollo desde 1964. Nuestro objetivo es verificar como los factores autoritarios se entrelazan al supuesto ideal de grandeza nacional.

Palabras clave: Fuerzas armadas, Ideología, Geopolítica, Brasil Potencia.

\section{Introdução}

Mal os canhões e fuzis de 1945 haviam sido silenciados, as populações acometidas pelas desgraças das duas grandes Guerras Mundiais viam-se envoltas em um novo conflito que não trazia, pelo menos aos tantos miseráveis filhos da guerra, qualquer esperança ou perspectiva de um fim próximo. A Guerra Fria, na sua dinâmica bipolar de poder e influências, iria favorecer o despontar de exércitos e seus déspotas em diversas nações e, longe de apenas defensores de suas fronteiras, essas instituições passariam militares a atuar como protagonistas na condução das políticas estatais, operando entre o autoritarismo interno e a defesa de um modelo econômico de Estado.

As origens desse militarismo, como ditava a historiografia, apontavam para um dado inquestionável: o breve século $X X$, marcado por duas grandes guerras, colocava os militares em evidência e, sua ascensão em diferentes estados, quando não óbvia, como uma necessidade (ESTENSSORO, 2003). Principalmente para a economia política de Guerra Fria e, em países de industrialização tardia, o militarismo e o imperialismo se tornariam momentos indissociáveis da evolução e manutenção do pretendido Desenvolvimento com Segurança. Acreditava-se nos casos em que casos as ditaduras haviam enveredado para a defesa ávida do capital frente ao comunismo, que os golpes de Estados decorrentes, concretizaram-se a partir da influência direta norte- 
americana, via ideologia de segurança nacional (FERREIRA, 1970; 1974).

Fruto do establishment militar americano, tal ideologia ${ }^{1}-$ segundo algumas análises ${ }^{2}$ - iria alastrar-se nas diferentes Escolas de Guerra na América Latina sendo transmitida quase sem modificações ou contestações. Entretanto, tais análises avaliam de maneira superficial o processo histórico de construção do ideário golpista que levou às ditaduras, pois, entendem que os chefes militares latino-americanos não tinham - e nem precisavam ter ideia do tipo de sociedade e de governo que iriam fundar. Ou seja,

${ }^{1}$ Sobre o fenômeno ideológico, diante das polêmicas que se avolumam em torno do termo, nos aproximamos de uma tradição marxista que assegura o poder prático da ideologia na mobilização social. Por isso, sustentando o caráter de consciência prática da ideologia, recusando o imperativo idealista que visa distinguir o falso do verdadeiro e, portanto, aquilo que entra na conceituação de ideologia e/o lhe escapa. Está claro que, nas sociedades divididas em classes, a ideologia é efetivamente a consciência de classe tomada operativa e consciente no antagonismo estrutural. Nesse sentido, o que determina a natureza das ideologias, acima de qualquer consideração, é o imperativo de se tornar praticamente consciente do conflito fundamental - a partir dos pontos de vista mutuamente excludentes das alternativas hegemônicas que se defrontam em determinada ordem social - com o propósito de resolvê-la através da luta. É a esta natureza de consciência social prática que importa reportar, assim como numa sociedade de classes, o caráter operatório e decisivo da ideologia na tomada de consciência dos conflitos e dos antagonismos, que levam à sua resolução até as últimas consequências. Na verdade, porém, a ideologia que pretendemos aqui aferir, não é, nem pode ser entendida, como ilusão ou superstição religiosa de indivíduos mal orientados, mas uma forma específica de consciência social, materialmente ancorada e sustentada como tal é insuperável nas sociedades de classe. Os interesses sociais, que se revelam ao longo da história e se entrelaçam de modo conflituoso, manifestam-se, no plano da consciência social, na grande diversidade de discursos ideológicos relativamente autônomos (mas de forma nenhuma independentes) que exercem forte influência mesmo sobre os processos materiais mais tangíveis do metabolismo social; Ver em MÉSZÁROS, 1996: 22-23 ou FERNANDES, 2003.

${ }^{2}$ Defensor de tal tese está COMBLIN, 1978. 
apostava-se numa inconsciência militar em relação a realidade a sua volta. Desse modo, a direita aparece como um simples fantoche ideológico sem história política ou capacidade de gerar suas próprias, doutrinas, ideologias e golpes.

A ascensão das Forças Armadas brasileiras - tanto de sua consolidação institucional quanto da construção de sua identidade - contraria tal renúncia de desejos. A inserção dos militares no Estado brasileiro $^{3}$ se deu notadamente a partir da ditadura do Estado Novo. Getúlio Vargas, apoiado em seu comando, promoveria a centralização e a institucionalização das Forças Armadas, cercando-as de um sentimento de coesão e identidade nacional. Apoiados numa política orçamentária provedora e munidos de cargos administrativos relevantes no Estado, os militares se viam inseridos na vida nacional com objetivos bem definidos que, de longe, extrapolavam suas funções. De um lado, a manutenção da ordem totalmente identificada com o autoritarismo; de outro, a condução política do país. E seja uma intervenção reformista ou conceito de poder moderador ${ }^{4}$, as ideologias, que propunham um papel político dos militares e pregavam um ideal de grandeza, fizeram parte constitutiva da instituição.

Dentre as diversas correntes de pensamentos que competiam no interior da instituição, aquela que melhor define os anseios militares e o próprio momento histórico que os acompanhava foi o pensamento geopolítico. Definida por seus ideólogos, no interior da Escola Superior de Guerra, a geopolítica seria "a política aplicada aos espaços geográficos". Melhor dizendo, se todo o Estado está assentado no meio geográfico que o provem, a geografia irá influenciar diretamente na formação interna desse Estado - inclusive de suas instituições e indivíduos - e de seu comportamento no cenário internacional. Segundo a ideia defendida pelos intelectuais militares, países de dimensões

${ }^{3} \mathrm{O}$ marco dessa consolidação das forças armadas, tanto na sociedade quanto da formação de uma ideologia especifica, remete a década de 1930. Ver também COELHO, 1976.

${ }^{4}$ Sobre o poder moderador ver em STEPAN, 1975. 
continentais e recursos naturais abundantes estariam destinados à grandeza, a serem grandes potências mundiais.

As influências teóricas desse discurso fazem parte de uma tradição de autores que se consagraram nos séculos XIX e XX. Totalmente atrelados às ideologias colonialistas, figuras como Friedrich Ratzel, Rudolf Kjellen e Nicolas Spykman, versaram suas hipóteses sustentando política e ideologicamente o conceito de nação superior. Essa geopolítica consolida-se, a saber, querendo explicar histórica e geograficamente o Estado e a construção de cenários e estratégias em situação de conflito. No entanto, esse Estado, proferido com frequência de modo genérico, geralmente concebido aquém da literatura que procura dar conta de sua origem e desenvolvimento histórico, aparece no discurso geopolítico como um dado a priori, desprovido de contradições internas e de movimento histórico ${ }^{5}$.

No Brasil, tais ideais consolidados, gerariam, entre outros, a crença de que "a terra sempre teve influência muito grande no destino do homem, assim como o país no dos povos e, juridicamente falando, o território no destino dos Estados" (OSÓRIO, 1970: 15). De acordo com essa visão, o Estado deveria guiar suas políticas, à luz do que a geopolítica propunha como ideal, pois nela descansaria o destino da nação. Historicamente, este discurso geopolítico que pregava o Destino Manifesto brasileiro como condição natural do Estado - predominou em boa parte da história republicana brasileira, integrado, nos anos 1920, aos círculos de pensamentos oficiais.

Capitaneado por militares expoentes como o Capitão Mário Travassos, o Brigadeiro Lysias Rodrigues e Everardo Backheuser, esse discurso geopolítico reflete uma obsessão pelo problema da unidade nacional ou integridade territorial, segundo a ideia de que uma grande extensão territorial só se torna uma vantagem política e econômica quando associada à ocupação e povoamento adequados, ao mesmo tempo em que, o poder central, bem

${ }^{5}$ Ver COSTA, 2010. 
localizado, possa estabelecer relações de coesão eficazes no todo territorial.

A impossibilidade material de estabelecer uma densa rede de ferro e rodovias é substituída inteligentemente pela rede de aerovias, que rapidamente cobre todo o país; a dificuldade de estender fios telegráficos por todo o território nacional é suprida com a implantação de postos radiotelegráficos por toda parte. Estimulouse a navegação marítima e fluvial, organizaram-se os planos nacionais ferroviários e rodoviários, ao mesmo tempo em que uma centralização enérgica era desenvolvida pelo Governo Federal, cortando uns regionalismos doentios, coibindo expansões políticas absolutas, estabelecendo uma só bandeira, a nacional, um só hino, o do país, sob a mística soberana; Grande, só o Brasil. (RODRIGUES, 1947: 57).

Desde então, o que poderia ser caracterizado como a primeira fase dos estudos geopolíticos brasileiros, seria, com o advento da Escola Superior de Guerra na década de 1950, incorporado e reestruturado ao pensamento militar ainda em fase de consolidação. Não obstante, as então intituladas "novas teorias" que surgiam e eram trazidas pelo general Golbery do Couto e Silva não apresentavam grandes superações aos ideólogos do período anterior e o cerne das formulações continuava a ser a expansão do Estado, a integração da nação e, consequentemente, a ideia-chave de que espaço é poder. Desse modo, essa geopolítica continuava a orientar-se pelos pressupostos do Estado como um organismo vivo e movido por interesses autônomos em relação à sociedade, mas identificado, agora, com um ideal de nação que pretendia representar. Ou seja, uma geopolítica anticomunista e centrada na defesa da civilização ocidental e cristã.

No mundo de hoje, o antagonismo dominante entre os EUA e a Rússia, polarizando todo o conflito, de profundas raízes ideológicas, entre a civilização cristã do Ocidente e o materialismo comunista do Oriente, 
e no qual se joga pelo domínio ou pela libertação do mundo, arregimenta todo o planeta sob o seu dinamismo avassalante a que não podem, não poderão sequer escapar, nos momentos decisivos, os propósitos mais reiterados e honestos de um neutralismo, afinal de contas, impotente e obrigatoriamente oscilante (COUTO e SILVA, 1981: 186-187).

A razão fundamental para esse embate entre os "dois mundos" era, segundo o autor, culpa do expansionismo soviético que procurava estabelecer um poder terrestre no bloco transcontinental euroasiático. Deste modo, o plano para conter o avanço soviético no ocidente estaria instrumentado por uma política de contenção, comandada pelos norte-americanos aqui no Ocidente, tendo o Brasil como parceiro preferencial. Essa foi a grande força do pensamento golberyano, equacionando em meio à bipolarização dos poderes, os objetivos de grandeza nacional e a inserção internacional do Estado como co-potência;

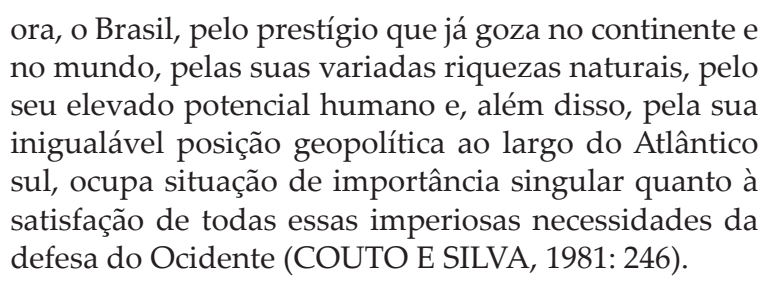

No entanto, cabe ressaltar que as formulações de Golbery e as de seus predecessores tinham em comum a afirmação de um Estado forte, centralizador, autoritário e coercitivo, como condição de elevação do poder nacional além das fronteiras.

Diante desse quadro, a Ditadura instaurada em 1964, representou a geopolítica um marco. Era a hora certa, acreditavam os ideólogos, para o país iniciar sua escalada dentro do cenário mundial. Após a consolidação do golpe em $1^{\circ}$ de Abril, os novos artífices prometeram à nação sua realização social plena, a superação do subdesenvolvimento e a diminuição das desigualdades pela integração total do Estado. Isto é, comprometeram-se a construir, 
com a aceleração possível, um poder nacional que faria do Brasil uma potência ouvida no conserto dos fortes e respeitada pelos fracos (FERREIRA, 1970: 29). Objetivos, estes, alcançados através da ilusão de ser possível o controle do Capital pelo alto e pela força. De acordo com o General Carlos de Meira Mattos, fiador basilar desta geopolítica de potência:

A dinâmica do processo revolucionário brasileiro está nos objetivos a conquistar a todo custo e em curto prazo, o desenvolvimento. $\mathrm{Na}$ medida em que esses objetivos venham a ser alcançados, se aliviará, progressivamente, a pressão política visando a substituir o nosso estilo de vida democrática e nossa paz social. Igualmente, cada passo que marque o avanço na conquista dos aludidos objetivos se refletirá no fortalecimento de nossa soberania, na consolidação da integridade territorial e no aumento do poder nacional (MATTOS, 1975: 103).

O Brasil Potência ${ }^{6}$ ocupou grande parte da produção geopolítica do período, não que ele fosse o único objeto de atenção, mas era o fundamental. Os militares acreditavam que o controle das contradições inerentes ao capitalismo era indispensável para assegurar o desenvolvimento econômico e a consequente projeção de poder do Estado. Para tal, bastaria a desagregação dos movimentos populares, uma vez que, a aceleração do desenvolvimento do capital industrial permitiria a diminuição das desigualdades regionais fortalecendo a coesão interna, assim como, propiciaria a formação de uma indústria bélica potente. Somado a isso, o entrelaçamento entre os "recursos naturais e posição estratégica privilegiada" do país, no continente, se garantiria o englobamento político-econômico para as forças que

\footnotetext{
${ }^{6}$ Ver sobre o projeto de Brasil potência em PEREIRA, 1997: 15-16. Para um detalhe como cada governo militar levou a cabo tais objetivos DEL VECCHIO, 2004.
} 
comandariam o país e eles dariam ao povo o destino que queriam: o único destino mensurável, o Brasil Potência.

Esse artigo pretende percorrer os principais aspectos que permeiam o discurso geopolítico e seu modelo de desenvolvimento proferido, a partir de 1964. Objetivamos mostrar o caráter ideológico de tais formulações e o modo como os fatores autoritários, coercitivos e desiguais estiveram entrelaçados ao suposto ideal de grandeza nacional. Como principal ponto, sustentamos a tese de que o modelo de desenvolvimento em questão não encontrou suporte na realidade do período, nem mesmo orientou os projetos econômicos dos governos, entretanto, foram fomentadores de um arcabouço de ideias que ao propor o Brasil potência e as possibilidades de sua realização, em curto prazo, criou uma situação em que as ações governamentais estariam justificadas.

\section{Potência, autoritarismo e desenvolvimento}

O enfoque dos trabalhos geopolíticos pós-64, além da projeção mundial do Brasil, assentava suas referências na posição estratégica do espaço nacional, nas potencialidades econômicas (tanto no campo da energia, quanto pelo produto interno bruto) e na capacidade industrial. Os dados eram assim divulgados:

Qualquer pessoa dedicada aos estudos geopolíticos, de qualquer nacionalidade, não pode deixar de reconhecer que somos donos de um país favorecido por características geográficas e humanas inerentes às grandes potências. Somos um subcontinente, nosso povoamento se processa em ritmo acelerado e nosso progresso econômico se expande "a olhos vistos", em que pese a interferência de inúmeros fatores perturbadores. Criamos uma nação mestiça, em que predomina o elemento branco, sem preocupações raciais e sem preconceitos de casta. Podemos nos orgulhar de ter forjado uma nação de 62 milhões de almas. (MATTOS, 1975: 117). 
De 1960 a 1974, períodos em que esse discurso vigorava, era perceptível, pelo menos no tocante à hegemonia territorial do Brasil, que "como princípios religiosos" os fundamentos da grandeza nacional estiveram sempre assentados em nossa geografia. Com o advento do golpe, a crença de que Brasil estava mais perto de seu destino se solidificou entre os círculos militares de onde emanavam as mais diversas soluções de manutenção do crescimento, encorajando soluções geopolíticas particulares ao período histórico. Dentre essas soluções, o desenvolvimento econômico iria despontar como a única forma de garantir a estabilidade ao país. O poder nacional e os fatores geográficos, assim como a educação, a saúde, os meios de transporte e as comunicações, foram todos, sem exceção, analisados sob o prisma da segurança nacional e do desenvolvimento. Nos primeiros anos após o golpe, a política de Castelo Branco de arrocho salarial, cassações e perseguições desenfreadas, intervenção direta nos meios sindicais ou qualquer outro setor opositor, mostravam a certeza dessa política.

Segundo os militares geopolíticos, essas atitudes eram necessárias para a manutenção de um clima estável, sem agitações sociais de qualquer espécie, uma tranquilidade alcançada apenas com uma legislação forte e coercitiva que pudesse diminuir as contradições internas. Imbricados em conceitos geográficos, surgem os temas relacionados, poder nacional e fatores geográficos, o poder nacional e "Segurança e Desenvolvimento", educação, integração e o poder nacional. Todos eles demonstram uma preocupação dos estudos - até então centrados nas relações externas - com os problemas internos.

Para os ideólogos geopolíticos, de 64, o Estado deveria ser absoluto e, para tal, só o autoritarismo tornaria viável a possibilidade de atingir os objetivos nacionais de grandeza. Essa afirmação não era uma novidade, uma vez que os gestores do Estado ditatorial concebiam a sociedade nacional como despreparada para executar qualquer tarefa, atribuindo a si mesmos o papel de mais aptos para garantir a realização dos objetivos hegemônicos. Mas, de fato, o que significava ser uma potência mundial? Quais eram seus pré- 
requisitos? Como saber se o Brasil ocupava essa condição no cenário internacional? E qual era seu poder real? Essas perguntas faziam parte do cotidiano da produção geopolítica ditatorial, expressas tantos nos boletins e nas palestras ministradas dentro da escola de guerra, quanto na produção externa da escola - representadas pelas revistas "Segurança e Desenvolvimento" e "A defesa nacional".

Em um pequeno ensaio intitulado: Conceito de Potência Mundial, publicado pelo departamento de estudos da Escola Superior de Guerra em 1976, o General Meira Mattos iniciou sua discussão propondo que o conceito de potência evoluiu progressivamente, no decorrer do século XX.

Antes que os extraordinários progressos técnicos-
científicos tivessem proporcionado ao homem os
meios eletrônicos de comunicação, as velocidades
supersônicas e os engenhos nucleares, o notável
professor sueco Rudolf Kjéllen, considerado o pai da
geopolítica, estabelecia como características de uma
grande potência, três atributos: espaço, liberdade de
movimento e coesão interna (MATTOS, 1976: 117).

Para Meira Mattos essa conceituação é válida, pois é dela que partem as grandes linhas de pesquisa geopolítica sobre o caráter das potências. Contudo, o momento histórico do qual fala o autor citado no documento e o modo esparso pelo qual os conceitos espaço e coesão - são apresentados, não atendem as necessidades do discurso no período. Era necessária uma conceituação mais completa que desse conta de colocar o Brasil em seu "devido lugar" na escala de desenvolvimento econômico e geográfico. Sob este prisma, argumenta Mattos:

Hoje em dia, grande potência é somente aquela cuja força coordenadora se exerce em dimensões mundiais; sua soberania deve estender-se sobre um vastíssimo território; deve dispor de imensas reservas de matériasprimas e de mão-de-obra especializada; sua capacidade de produção deve permitir-lhe a fabricação, em grande quantidade, de armas modernas de alto custo, e de

Idéias - Rev. Inst. Filos. Ciênc. Hum. UNICAMP, v.6, n.2, p. 255-281, jul/dez. 2015 
ceder, gratuitamente, enormes porções de produtos manufaturados, pois este é o método contemporâneo de fazer aliados [...] (MATTOS, 1976: 118).

A passagem acima apresenta para a geopolítica ditatorial um corpo "doutrinário" melhor desenvolvido e detalhado, principalmente no caso da afirmação do território como fonte de poder e projeção. Existem inúmeras classificações - no discurso geopolítico como um todo - para estabelecer a hierarquia entre os países. Muitas delas encontram, nas correntes brasileiras, fãs incondicionais, principalmente aquelas que enfatizam as capacidades do país. Entre os exemplos mais citados, destacamos as tipologias elaboradas por Hans Morgenthau, Nicolas J. Spykman e A. P. Kenneth Organsky.

Se levarmos em consideração o fato de que o discurso geopolítico de potência segue em três grandes vertentes - política, econômica e social -, os critérios adotados por Organsky dão conta da vertente econômica. Não existe um abandono dos outros elementos, porém o produto interno bruto é privilegiado como forma de estabelecer uma hierarquia nacional. Portanto, a variação do PNB dos países marca a ascensão ou declínio de cada nação. Não é necessário ir muito longe para compreender o motivo da absorção dessas ideias pelos geopolíticos no período do milagre no Brasil. O ideólogo Meira Mattos, ao apresentar Organsky em seus escritos, busca relacionar o enfoque econômico e a população, com o poder político-militar. Diz ele:

O poder de uma nação moderna apoia-se consideravelmente no tamanho de sua população, com inúmeros expressivos, uma nação pode sobrepujar suas deficiências, sem eles, grande poder é impossível. Hoje, a importância crucial do volume de população é ofuscada pelas imensas diferenças em desenvolvimento econômico, que torna possível a nações de tamanho médio dominar o mundo [...].

\footnotetext{
${ }^{7}$ Ver em ARON, 2002.
} 
Uma grande população assegura o poder humano para forças armadas poderosas, assegura o trabalho para produzir grande riqueza nacional, assegura os consumidores que fazem o papel de mercado para outras nações, assegura os contribuintes de impostos que subscreverão os enormes custos do jogo da política mundial no presente estágio e assegura a ousadia para correr os riscos necessários de tal jogo. É difícil fugir à conclusão de que grandes populações fazem grandes nações. (MATTOS, 1976: 121).

Do mesmo modo que a apropriação de Organsky pelo discurso destaca as populações como um dos elementos de grandeza in potencial, a apreensão, tanto de Spykman quanto de Morgenthau, ressaltou os valores geográficos nessa composição. Morgenthau, por exemplo, apoia o poder nacional na geografia, nos recursos naturais, na capacidade industrial proveniente, no preparo militar, na população nacional, na moral nacional, na qualidade de diplomacia e força da liderança nacional. Ao fazer uma releitura desses autores, o discurso geopolítico, representado nesse caso por Meira Mattos, buscava sintetizar as necessidades do país naquele momento:

Superfície do território, natureza das fronteiras, quantidade de população, ausência ou presença de matérias-primas, desenvolvimento econômico e tecnológico, capacidade financeira, homogeneidade étnica, grau de integração social, estabilidade política e coesão interna [...] geografia, recursos naturais, capacidade industrial, grau de eficiência militar, população, caráter nacional, moral nacional (MATTOS, 1976: 119).

O quadro apresentado até aqui, nada mais fez senão justificar as ações repressivas e centralizadoras do governo ditatorial. Porém, para o discurso geopolítico não bastava apenas justificar a "revolução", mas sim encaixar o Brasil no ranking das grandes nações como uma potência de médio porte, ao lado do 
México, Índia, China e Argentina, sendo o Brasil e a China "as duas potências médias que possuem melhores condições de aspirar a uma passagem para o segundo grupo, das superpotências de $2^{a}$. Classe". Continua o autor:

A apreciação dos atributos essenciais de potência selecionados por tantos estudiosos da ciência política e da geopolítica revela que nós, brasileiros, possuímos todas as condições para aspirarmos a um lugar entre as grandes nações do mundo. Em termos de geografia, temos um território de dimensões continentais, com imenso litoral debruçado sobre o Atlântico Sul e maior fronteira terrestre, $15.400 \mathrm{~km}$ confinado com dez países sul-americanos. (MATTOS, 1976: 122).

As potencialidades geográficas foram as determinantes principais que tornavam o Brasil, na visão geopolítica, uma nação poderosa. Quais sejam os critérios definidos de potência, primeira ou segunda classe, os militares destacavam apenas duas superpotências como dignas de referência: EUA e URSS. Para a geopolítica, o quadro comparativo entre outros países era a melhor forma de situar o atual momento em que se encontrava o Brasil. Segundo o grosso dos discursos, a comparação era feita trazendo ao embate nações que, em fator de suas dimensões, apresentavam requisitos semelhantes no que tange ao espaço físico e população.

Por isso, a China - com um território de 9,59 milhões de quilômetros quadrados e mais de 1 bilhão de habitantes - e a Índia - com 3.053 milhões de quilômetros e na mesma ordem de habitantes - eram os principais objetos comparativos por serem candidatas à nações dominantes. O general Meira Mattos, valendose das categorias apresentadas por Organsky, chegou à conclusão de que a cifra exata para o número de habitantes versus território devia ser da ordem de 200 milhões de habitantes como o quantum mínimo para a grande potência contemporânea (MATTOS, 1970: 83). Ainda que existissem outras nações aspirantes, no caso a Europa Ocidental integrada e o Japão - considerando os aspectos muito particulares - para o General, do ponto de vista da posse de 
recursos naturais, a China e o Brasil estavam também na dianteira. Isso porque as dimensões continentais somadas à posição estratégica, face aos grandes oceanos, abririam possibilidades infinitas para agricultura, além de incalculáveis minerais no interior e na plataforma marítima.

É necessária aqui uma pausa para reflexão. Como de praxe na ideologia geopolítica brasileira, principalmente a de 64 , as soluções efetivas para problemas considerados práticos - como um plano sistemático de exploração mineral ou mesmo um modo de usar a dita posição estratégica do Brasil - nunca são explícitas e quando se propõem, jamais são contundentes. A explicação correta para essa questão é simples: não são explícitas e nem contundentes porque elas não existem. A função que assumiu esse discurso no período ditatorial era a de justificador das ações políticas, econômicas e sociais centradas nas decisões dos governos em exercício. Nesse sentido as carências metodológicas são explicadas, uma vez que o discurso serviu muito mais como uma "agência de propaganda" do que instrumento efetivo de ação.

Dessa forma, a ideologia geopolítica de 64, como foi apresentada até aqui, se apegou no que tange ao projeto de potência, aos dados estatísticos e comparativos que não revelavam nada de substancial. Um exemplo claro, ainda no universo comparativo, é o modo como a capacidade industrial, tecnológica e científica era analisada. Para Meira Mattos, enquanto Japão e a Europa Ocidental integrada já podiam ser computados como nações em estágios de mais alto nível, o Brasil, a China e a Índia se encontravam em plena revolução desenvolvimentista. O General, falando da década de 70, propunha que nos próximos 25 anos os dois países teriam que manter programas de desenvolvimento em ritmo acelerado e corretamente orientados, ainda que por caminhos opostos. Isto é, manter o acúmulo de capital e a expropriação das classes subalternas intactas ${ }^{8}$.

\footnotetext{
${ }^{8}$ Aspectos do "milagre econômico" ver ARRIGUI, 1998.
} 
[...] enquanto a China segue o rumo do desenvolvimento socialista numa sociedade fechada, o Brasil se orienta pelo desenvolvimento capitalista sob controle e no âmbito de uma sociedade democrática aberta (MATTOS, 1970: 84).

Diante de tais necessidades, o caso da Índia não foi esquecido, mas, nesse ponto, a comparação serviria a outros propósitos. O país era tido como uma sociedade fraca por não ter conseguido superar as limitações - assim chamadas, em relação às crenças místico-religiosas - promovendo uma sociedade estática e compartimentada em castas e superstições. Para os ideais geopolíticos, uma sociedade como essa estava em desacordo direto com o que seria uma sociedade capitalista, tecnológica e civilizada. Ou seja, nas palavras do General, "nosso conceito de desenvolvimento é o democrático e encontra suas raízes na filosofia cristã ${ }^{\prime \prime \prime}$ (MATTOS, 1975: 103).

Nessa linha de raciocínio, apresentada por Meira Mattos, a Índia ficaria para trás na corrida das potências já que não havia compreendido - como fez o Ocidente - que o desenvolvimento e os "ideais" que guiam o Estado "democrático" capitalista, são a única forma de paz social. E completa Meira Mattos ao tratar do caso brasileiro:

A dinâmica do processo revolucionário brasileiro está nos objetivos a conquistar a todo custo e a curto prazo, traduzidos na política de desenvolvimento. $\mathrm{Na}$ medida em que esses objetivos venham a ser alcançados, se aliviará, progressivamente, a pressão política visando a substituir o nosso estilo de vida democrático, demolir as nossas concepções morais e espirituais de existência e destruir a nossa paz social. Igualmente, cada passo que marque o avanço na conquista dos aludidos objetivos se refletirá no fortalecimento de nossa soberania, na consolidação da

${ }^{9}$ MATTOS, 1975: 103. 
integridade territorial e no aumento do poder nacional (MATTOS, 1975: 103).

\section{Modelo geopolítico de desenvolvimento}

No ano de 1974, a revista $A$ defesa nacional organizava uma de suas edições bimestrais, dos meses de janeiro e fevereiro, com um conjunto de artigos que visava estabelecer um programa de desenvolvimento baseado nas potencialidades e deficiências geográficas do Estado brasileiro. Mais do que a simples construção de um modelo, os vários artigos tinham, como missão, discutirem a política em vigor e buscar suas irregularidades, principalmente quando essas não contemplavam as expectativas geopolíticas em relação à aplicação de um modelo econômico que privilegiasse as potencialidades geográficas do Estado. Desse modo, um dos artigos escritos por Nilson Holanda, buscava reconhecer as principais características do modelo brasileiro de desenvolvimento instaurado naquele momento. Inicia o autor:

Contrastando fortemente com a situação de virtual estagnação econômica de há 10 anos, o país poderá completar em 1973 (a serem válidas as previsões de crescimento de $10 \%$ no corrente ano) um período ininterrupto de 6 anos com taxas de crescimento do PIB superiores a $9 \%$ a.a. A taxa de crescimento alcançada em 1971 - 11,3\% - foi a mais alta de que se tem notícia na história econômica do país. Todas as principais metas do atual Plano Nacional de desenvolvimento (1972/1974) têm sido alcançadas ou superadas nos últimos dois anos. Estendendo-se até 1980 as projeções desse plano, o Brasil alcançaria o final da década um PIB de US\$ 103.400 milhões e uma renda per capita de US\$ 850. (HOLANDA, 1974: p. 6).

De acordo com o autor, o Brasil imprimiu, para atingir esse desenvolvimento, uma política flexível, gradualista e pragmaticamente sustentada em bases fortes. Esse tipo de política 
gradualista - ou por estágios - se fundamentava no pressuposto de que o desenvolvimento é uma tarefa de longo prazo e o crescimento acelerado autossustentado exige a criação prévia de algumas condições básicas, em termos de reformas institucionais e de modificações da estrutura do sistema econômico. No caso brasileiro, essa sequência compreendeu em primeiro lugar, a construção de uma economia de mercado através da eliminação das distorções e desajustes de um secular processo inflacionário, que nos primeiros anos da década de 60, tendia perigosamente para a hiperinflação; em segundo lugar, a aceleração da taxa de crescimento econômico através da eliminação dos pontos de estrangulamento da economia, particularmente no que se refere ao setor externo (HOLANDA, 1974: 8).

O reflexo dessa política, apontada pelo autor, se insere diretamente no entendimento de que o desenvolvimento econômico é o regulador de todo e qualquer problema social, já "que os efeitos do acelerado desenvolvimento são disseminados para todas as classes sociais e regiões" (HOLANDA, 1974: 8), promulgando uma comoção nacional que volta seus esforços à grandeza do país. Fazendo apologia aos aspectos e à eficácia do modelo apresentado no primeiro Plano Nacional de Desenvolvimento (IPND) e absorvendo o corpo ideológico do programa, o discurso reafirmava a preocupação com o desenvolvimento econômico integrado. Isso significava alcançar, no plano social, de um lado a melhoria da distribuição regional de renda - através de uma ocupação territorial ordenada que permitisse o melhor aproveitamento do seu espaço físico -; de outro lado, dentro de cada região, a elevação e a ampliação das oportunidades de avanço social. Antes de compreender de que modo a geopolítica insere a integração nacional no modelo de desenvolvimento prometido pela ditadura militar, é necessário entender a comparação feita da política antes e depois de 1964.

São identificados pelos ideólogos dois momentos e modelos distintos de um programa de desenvolvimento, um que vigorou de 1945/64 e o outro de 1964/73. De acordo com o discurso, o primeiro orientava-se por uma política "indiscriminada" de substituição de 
importações, elevado protecionismo e financiamento inflacionário dos investimentos. Essa política fundamentada nesses mecanismos permitiria alcançar, em curto prazo, uma elevada taxa de crescimento, gerando, porém, ao longo do processo, distorções e contradições internas ao Estado, que levam o sistema econômico a uma situação de estagnação e crise. Isto é:

\begin{abstract}
O protecionismo indiscriminado associado a uma inflação acelerada, pode induzir um certo crescimento industrial, durante algum tempo, mas termina por limitar esse crescimento na medida em que provoca a formação de uma estrutura industrial ineficiente, em que não são levados na devida consideração os problemas de competitividade, custos e avanço tecnológico. Ademais, paralelamente à progressiva integração do setor industrial, essa ineficiência tende a transmitir-se, em cadeia, por todo o sistema econômico (HOLANDA, 1974: 20).
\end{abstract}

Nessa visão, o processo inflacionário tende a ganhar velocidade transformando-se em inflação aguda, o que evidenciaria essas distorções. Contudo, devemos entender quais sãos os verdadeiros interesses desses ideólogos ao promulgar essas afirmações. Nesse caso, justificar a "revolução" e seu modelo econômico, "repetia-se então no país o já conhecido panorama de crises que se segue a uma situação de desregramento financeiro e desequilíbrio monetário", o que levaria não só a uma crise econômica ou estagnação, mas ao principal dos medos, uma tendência a hiper-inflação, fuga de capitais, agitação sindical e déficits descontrolados e instabilidade política.

O principal problema apontado no primeiro modelo econômico, anterior ao golpe, era ser fomentador de desequilíbrios e instabilidades geradoras de focos insurrecionais. Esse ponto demonstra uma absorção da geopolítica dos objetivos ditados pela Segurança Nacional no período. Houve uma mudança na concepção de segurança, após a década de 1960, com a edição do Decreto-Lei n 314 de 1967, ou Lei de Segurança Nacional, 
deslocando o eixo das discussões quanto ao conceito de segurança. Essa lei possuía uma abrangência muito grande e isso era vital para que pudesse ser estabelecida uma política de desenvolvimento sem maiores atritos interclasses. Possibilitaria também ao grupo hegemônico, detentor do controle do aparelho do Estado, colocar em marcha seus planos de elevar o país ao status de potência.

Já mostramos que a garantia da ordem para os militares era fundamental à "implementação" do lema "Segurança e Desenvolvimento," com o intuito de alcançar, para o Brasil, um determinado grau de desenvolvimento, almejando a categoria de potência média. Para isso, era necessária a coesão interna, mesmo que ela fosse alcançada pela via autoritária. Qualquer possibilidade de conflito interno colocaria em risco esse intento. É possível perceber a ligação, quase que literal, entre a Lei de Defesa e Segurança Nacional de 1976 e o modelo de desenvolvimento proposto pela geopolítica. Sobre a lei dizia-se o seguinte:

“[...] a) a soberania por meio da preservação da integridade territorial, do patrimônio e dos interesses nacionais; b) o Estado de Direito e as instituições democráticas; c) a preservação da coesão e da unidade da Nação; d) a salvaguarda das pessoas, dos bens e dos recursos brasileiros ou sob jurisdição brasileira; e) a consecução e a manutenção dos interesses brasileiros no exterior; f) a projeção do Brasil no concerto das nações e sua maior inserção no processo decisório internacional; e g) a contribuição para a manutenção da paz e da segurança internacionais. (HOLANDA, 1974: 22).

No que tange ao binômio segurança e desenvolvimento, já devidamente analisados por inúmeros trabalhos, não existem grandes diferenças entre o que se falava no interior do IPND, a Lei de Segurança Nacional e o modelo econômico geopolítico. Dos três citados, podemos inferir a geopolítica como aquela que melhor reorganizou ideologicamente esses elementos de segurança e desenvolvimento - presentes no universo tanto militar quanto civil - em seus postulados, apropriando-se daqueles que melhor 
atendiam as suas necessidades de expansão, ou seja, a já comentada integração nacional.

Na ótica da geopolítica, pouco adiantava possuir milhões de quilômetros quadrados, recursos minerais dos mais variados, uma vasta e riquíssima rede hidrográfica se o território não fosse todo ocupado. Daí a integração nacional tornar-se imprescindível para um país que tem a pretensão de ser reconhecido como possuidor de um poder nacional invejável e para manter-se seguro, fora e dentro de suas fronteiras. Essa é a razão principal a que se deve a atenção dos geopolíticos, principalmente pós 64 . Nesse contexto, o tema integração se fez presente, por muitas vezes, em todos os planos nacionais. Tanto o plano de metas quanto o IPND buscavam alcançar uma integração no sentido nordeste-sul. Ou seja, estabelecer-se-iam polos regionais, no sul e no nordeste, no planalto central e na Amazônia, dessa maneira, interrompendo o fluxo migratório em direção ao sul do país. No mesmo compasso, o IIPND, em vigor no governo de Ernesto Geisel - já dentro e uma concepção de Brasil potência emergente - buscava a estratégia de integração nacional em programas assistenciais como: Programa de Integração Nacional (PIN), Programa de Redistribuição de Terras do Norte e Nordeste (PROTERRA), Programa Especial para o Vale do São Francisco (PROVALE) e Programa de Desenvolvimento do Centro-Oeste (PRODOESTE).

De acordo com Meira Mattos, os estímulos do espaço brasileiro encontravam-se essencialmente na existência de imensa massa interior, distante do mar e não favorecidas por saídas oceânicas fáceis. Seu desenvolvimento, portanto, sugeriria a implantação de áreas interiores de interesse econômico, capazes de se modernizarem e sobreviverem vinculadas a um estímulo regional. Essas áreas deveriam se integrar sem dependerem, em nada, dos oceanos. Buscando compreender o processo mal acabado de interiorização, preconizado na "Marcha para o Oeste", o geopolítico vai dizer que em termos de fronteiras políticas, as gerações posteriores, apesar de tentarem, não conseguiram concretizar a interiorização do país iniciada pelos bandeirantes. Diz o autor, 
[...] durante 200 anos tentamos a conquista de nosso interior e particularmente da imensa bacia amazônica apoiados em estratégia essencialmente fluvial. Fracassamos porque a navegação fluvial é caprichosa: não nos leva onde queremos; a navegação dos rios amazônicos sofre influência das estações de águas altas e águas baixas; há inúmeras quedas e cachoeiras que interrompem a navegação da maioria dos cursos d água (MATTOS, 1977: 107).

Sua crítica se insere diretamente no modo como os estudos geopolíticos anteriores - a exemplo de Mário Travassos - priorizavam a vasta rede hidrográfica do Brasil como fator de garantia para ligar as regiões afastadas. Nada mais justo, uma vez que a década de 1970 permitia o uso de estratégias adequadas, as novas tecnologias. Sobre o novo modelo de integração proposto, escreve o General:

[...] mudamos de estratégia nos anos 50, e começamos a implantá-la nos anos 60. A nova tentativa seria a conquista do planalto Central, onde se encontra o divortium aquarum entre as três maiores bacias brasileiras - do Prata, do Amazonas e do São Francisco; montados nesse divisor (instalação de Brasília), tentaríamos baixar à planície amazônica pelos grandes espigões que separam as águas dos afluentes da margem sul do 'grande rio'. Assim o fizemos, descemos pelo divisor que separa o Tocantins do Araguaia para alcançar Belém na foz do Amazonas. Descemos pelo espigão que separa o Xingu do Tapajós, até Santarém, no baixo amazonas. Baixamos pelo espigão separador das bacias do Madeira e do Tapajós para chegar a Manaus, no médio amazonas. $\mathrm{O}$ eixo desse empreendimento animou-nos. Depois veio a grande veia transversal, cortando os espigões de leste para oeste, e ligando entre si as artérias longitudinais que seguiram esses divisores - a Transamazônica [...] (MATTOS, 1977: 108). 
A forma eloquente e romantizada de tratar o assunto esconde a necessidade de se apropriar de políticas integracionistas, promovidas pelos governos militares e trazê-las para o universo geopolítico, assumindo as responsabilidades - pelo menos teóricas - pela execução das obras. Longe de ser uma verdade, uma vez que os projetos aconteciam sem a consulta prévia desses geopolíticos e, muitas vezes, as políticas adotadas não tinham objetivos geopolíticos, mas se inscreviam em um quadro global de planejamento em que se procurava atingir todo o país, não com finalidades geoestratégicas, porém pensando em termos econômicos, a política de integração visava garantir locais onde se pudesse produzir mais e melhor. No caso da construção da rodovia Transamazônica, o mais obvio é que sua criação visava explorar as fontes de riquezas infinitas que a floresta podia fornecer. É inegável que isso promoveria uma integração e, até mesmo, a construção de estradas ligando as regiões vizinhas, porém os objetivos estratégicos militares de defesa frente a agressões não fizeram parte - nem tinha lógica - do planejamento governamental.

O sonho de grandeza, co-potência ou mesmo de uma potência mundial plena - se as condições políticas permitissem - era para a ideologia geopolítica uma condição natural concedida pela "natureza" ao Estado brasileiro. Ao permitir uma vasta extensão territorial, posicionamento estratégico privilegiado e recursos naturais infindos, ela, "a natureza", atestava em seus planos o nosso destino promissor. No entanto, é visível que o determinismo geográfico que endossou essa tese, metodologicamente falando, não carregava na equação o fator humano. Os projetos políticos distintos, os anseios e pretensões controversas, a luta entre as classes e os grupos sociais detentores diretos do poder no Estado, estavam apagados. Ou seja, não se considerava a dinâmica democrática como um ponto positivo. E se de fato, as políticas de Estado tinham necessariamente que lidar com essas determinações, o discurso geopolítico só tinha a oferecer sua contribuição propagandística; e ao país restaria esperar seu destino, que assim como economia na década de 70, seria milagroso: 
Pretendemos chegar ao umbral do ano 2000 desfrutando de uma posição de destaque entre as sociedades democráticas mais desenvolvidas do mundo. Nossa meta é persistir no ritmo de desenvolvimento que vem sendo alcançado, de sorte a criar uma sociedade moderna, progressista e humana; uma sociedade em que o homem alcance sua plena realização, possa realizar todas as dimensões de suas necessidades e aspirações (MATTOS, 1977: 138)

\section{Fontes}

COUTO E SILVA, Golbery do (General). Planejamento estratégico. Brasília: Editora UnB, 1981.

. Geopolítica do Brasil. Rio de Janeiro José Olympio, 1981.

FEHLBERG, Carlos. A revolução e sua presença no sul. In Revolução evolução. Brasília: AERP, 1970.

MATTOS, Carlos de Meira. Doutrina política de potência. In Revolução e Evolução. AERP, 1970.

. Brasil - Geopolítica e Destino. Rio de Janeiro: Ed José Olympio, 1975.

- MATTOS, Carlos de Meira, Geopolítica - a geopolítica e a teoria da forma e do espaço dos estados. 1976. . Conceito de potência mundial. 1976.

- A geopolítica e as projeções do poder. Rio de Janeiro: Biblioteca do Exército, 1977.

RODRIGUES, Lysias. Geopolítica do Brasil. Rio de Janeiro: Biblioteca Militar, 1947.

TRAVASSOS, Mário. Estrutura geo-militar do Brasil. In Cultura Política 1. Rio de Janeiro, 1941. 

Editora nacional, 1947.

\section{Boletins da Escola Superior de Guerra, por ano de publicação}

OSÓRIO, Oromar Osório, Aspectos militares de natureza geográfica - aspectos de posição, extensão territorial, estrutura da área e clima, face aos problemas militares do país. 1960.

Equipe do Departamento de Estudos, A influência dos fatores geográficos sobre o poder nacional. 1961.

TOSTA, Octávio, (coronel), Teorias geopolíticas. 1961.

GUIMARÃES, Fabio de Macedo Soares, O poder nacional fundamentos e fatores geográficos. 1962.

ARAÚJO, Antônio Andrade, (coronel) Poder Nacional, Fundamentos e Fatores Militares. 1963.

LIMA, Alceu Amoroso, Interpretação dos interesses e das aspirações do povo brasileiro: análise sociológica. 1963.

SOARES, Edmundo de Macedo, Interpretação dos interesses e das aspirações do povo brasileiro: análise econômica. 1963.

MALAN, Alfredo Souto (general), Geopolítica e Segurança Nacional. 1963.

ALMEIDA, Jorge de Sá, A situação continental: Os grandes problemas do continente Americano. 1964.

TOSTA, Octávio, Geopolítica aplicada - Aspectos Mundiais e SulAmericanos. 1966.

PELLEGRINI, João Jacobus, Os principais problemas internacionais com que se defronta o Brasil como potência em ascensão. 1972.

HOLANDA, Nilson, As principais características do modelo brasileiro de desenvolvimento. 1974. 


\section{Referências Bibliográficas}

ARON, Raymond. Paz e Guerra entre as nações. São Paulo/Brasília: Imprensa Oficial do Estado/Universidade de Brasília/Instituto de Pesquisa de Relações Internacionais, 2002.

ARRIGUI, Giovanni. A ilusão do desenvolvimento. Petrópolis: Editora Vozes, 1998.

ASSUNÇÃO, Vânia Noeli Ferreira. O Satânico Doutor Go: A ideologia Bonapartista de Golbery do Couto e Silva. Tese de mestrado defendida no Programa de Ciências Sociais da PUC-SP, 1999.

BOARATI, Vanessa. A discussão entre economistas na década de 1970 sobre a estratégia de desenvolvimento econômico II PND: motivações custos e resultados, dissertação de mestrado apresentada à faculdade de economia, administração e contabilidade. São Paulo: USP, 2003.

COELHO, Edmundo Campos. Em Busca de Identidade: o Exército e a politica na sociedade brasileira. Rio de Janeiro: ForenseUniversitária. 1976.

COMBLIN, Joseph. A ideologia da segurança nacional. Rio de Janeiro: Civilização brasileira, 1978.

COSTA, Wanderley Messias da. Geografia politica e geopolítica: discursos sobre o território e o poder. 2 ed. São Paulo. Edusp, 2010.

DEL VECCHIO, Ângelo. Política e Potência no regime militar brasileiro. In Revista Projeto História n. 29 tomo 1. São Paulo: Educ 2004.

ESTENSSORO, Luís. Capitalismo, Desigualdade e Poder na América Latina. Tese de doutorado apresentada ao Departamento de Sociologia da Faculdade de Filosofia, Letras e Ciências Humanas (FFLCH) da Universidade de São Paulo, 2003. 
FERNANDES, Florestan. A consciência revolucionária da História. In MARX, Karl \& ENGELS, Friedrich: história. Coleção grandes cientistas sociais, n.36. São Paulo: Editora Ática, 2003.

FERREIRA, Oliveiros S. La Geopolítica y El Ejercito Brasileño. In BELTRÁN, Virgilio Rafael. El papel político y social de los Fuerzas Armadas en América Latina. Caracas: Monte Ávila Editora, 1970.

MÉSZÁROS, István. Filosofia. O poder da Ideologia. São Paulo: Boitempo, 2004.

OLIVEIRA, Eliézer Rizzo de. As Forças Armadas: política e ideologia no Brasil. Petrópolis: Vozes, 1976.

PEREIRA, Maurício B. Estado Novo: a constituição das bases do partido militar e do projeto Brasil Potência. Premissas Caderno do Núcleo de Estudos Estratégicos da Unicamp v 15-16, 1997.

STEPAN, Alfred. Os Militares na Política. Rio de Janeiro: Artenova, 1975. 